2011-02-18

\title{
The Effects of Color on Visual Short-Term Memory
}

TaeLynn Johnson

Zachary Burk

Kassandra Larson

Annalisa Ellsworth

Follow this and additional works at: https://scholarsarchive.byu.edu/studentpub

Part of the Psychology Commons

\section{BYU ScholarsArchive Citation}

Johnson, TaeLynn; Burk, Zachary; Larson, Kassandra; and Ellsworth, Annalisa, "The Effects of Color on Visual Short-Term Memory" (2011). Student Works. 127.

https://scholarsarchive.byu.edu/studentpub/127

This Presentation is brought to you for free and open access by BYU ScholarsArchive. It has been accepted for inclusion in Student Works by an authorized administrator of BYU ScholarsArchive. For more information, please contact scholarsarchive@byu.edu, ellen_amatangelo@byu.edu. 


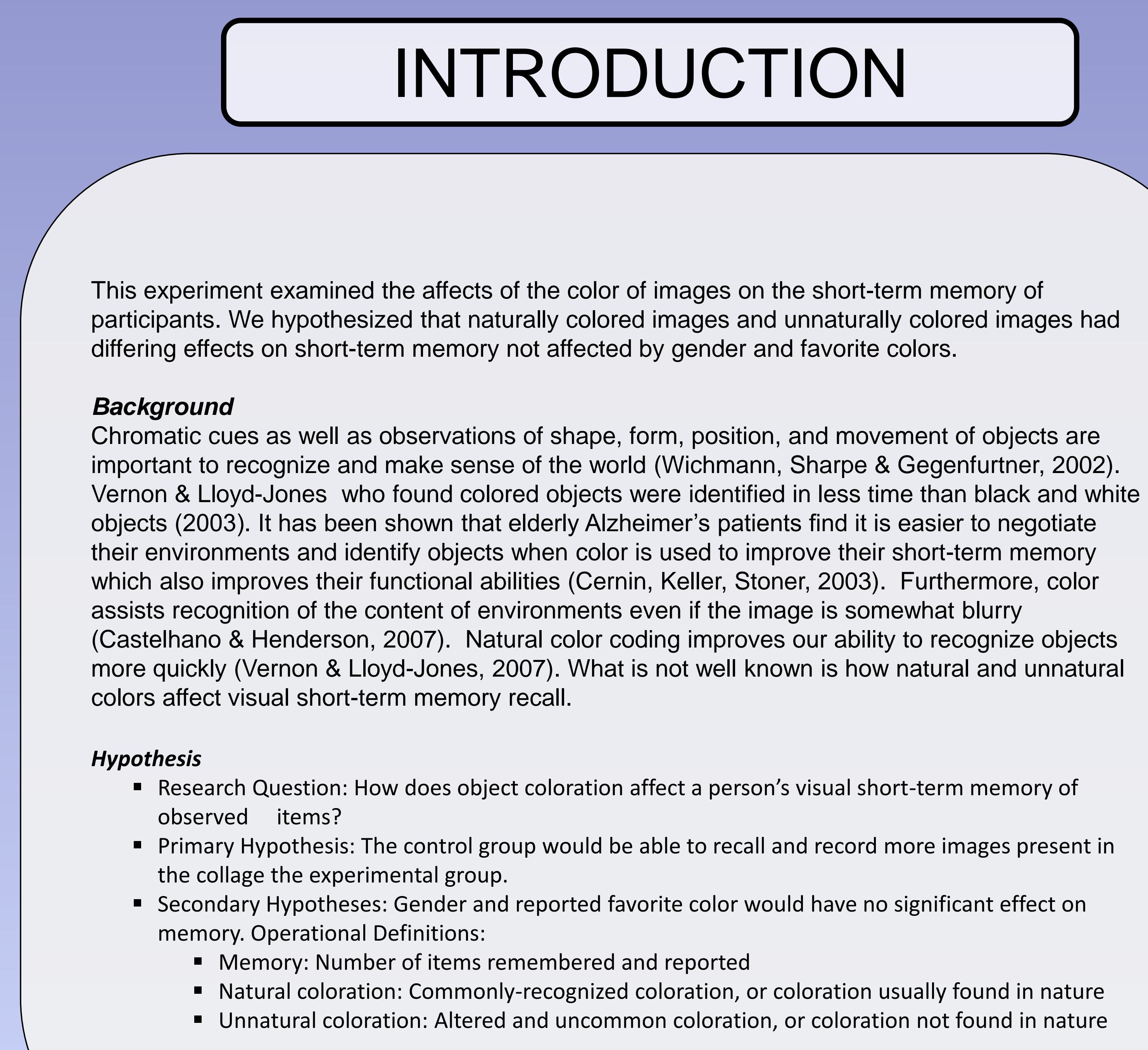

\section{METHOD}

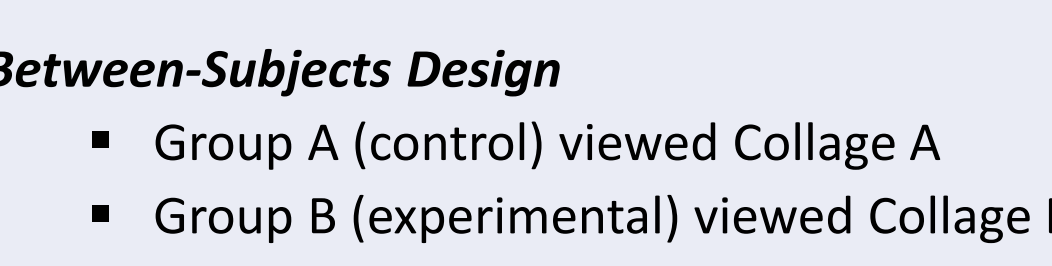

Independent variable: Which collage was viewed
Dependent varible: Number of I Imager

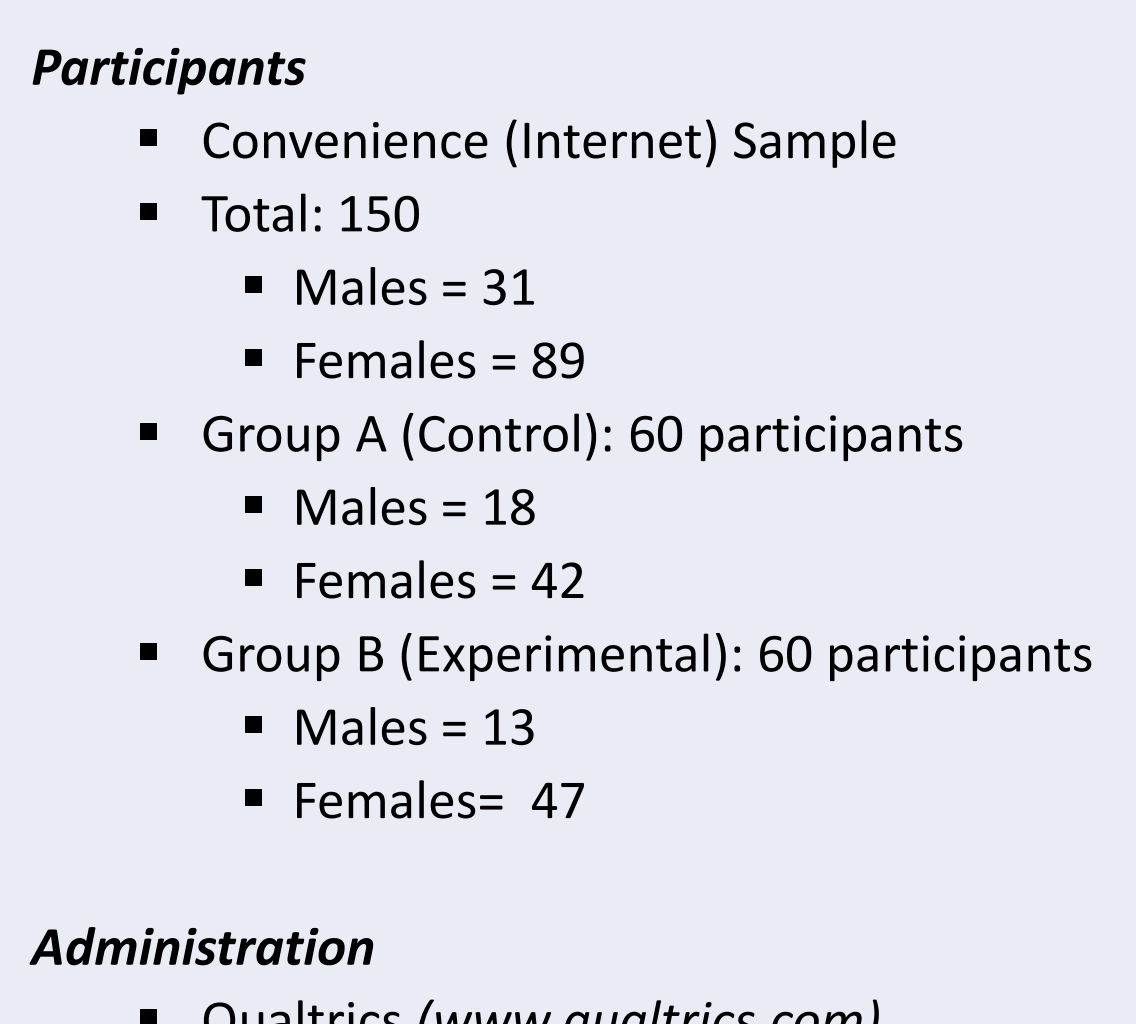

Administration
$:$ Quatrics (www.qualtrics.com)
SonA (www.byu.sona-systems.com)$$
\text { Measures }
$$

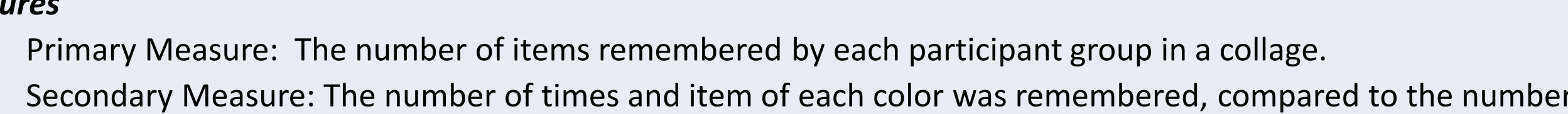

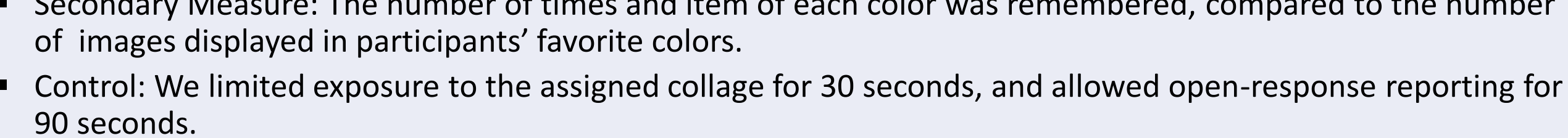

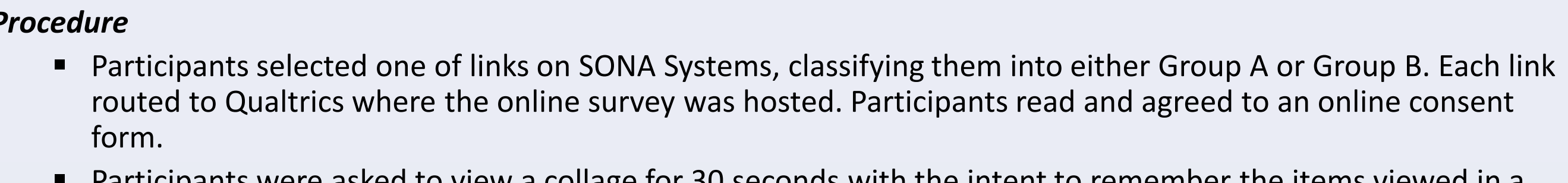

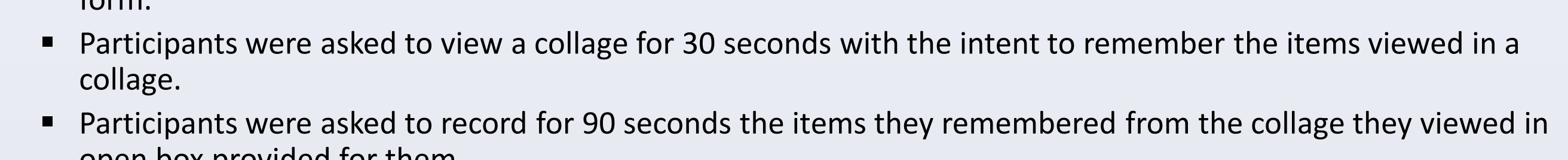
open box provided for them.
Participants were then asked to answer demographic questions, including age range, gender, major in colles.

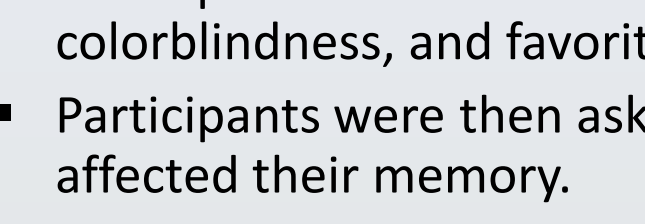

Zachary Burk, TaeLynn Johnson, Kassandra Larson \& Annalisa Ellsworth

Brigham Young University

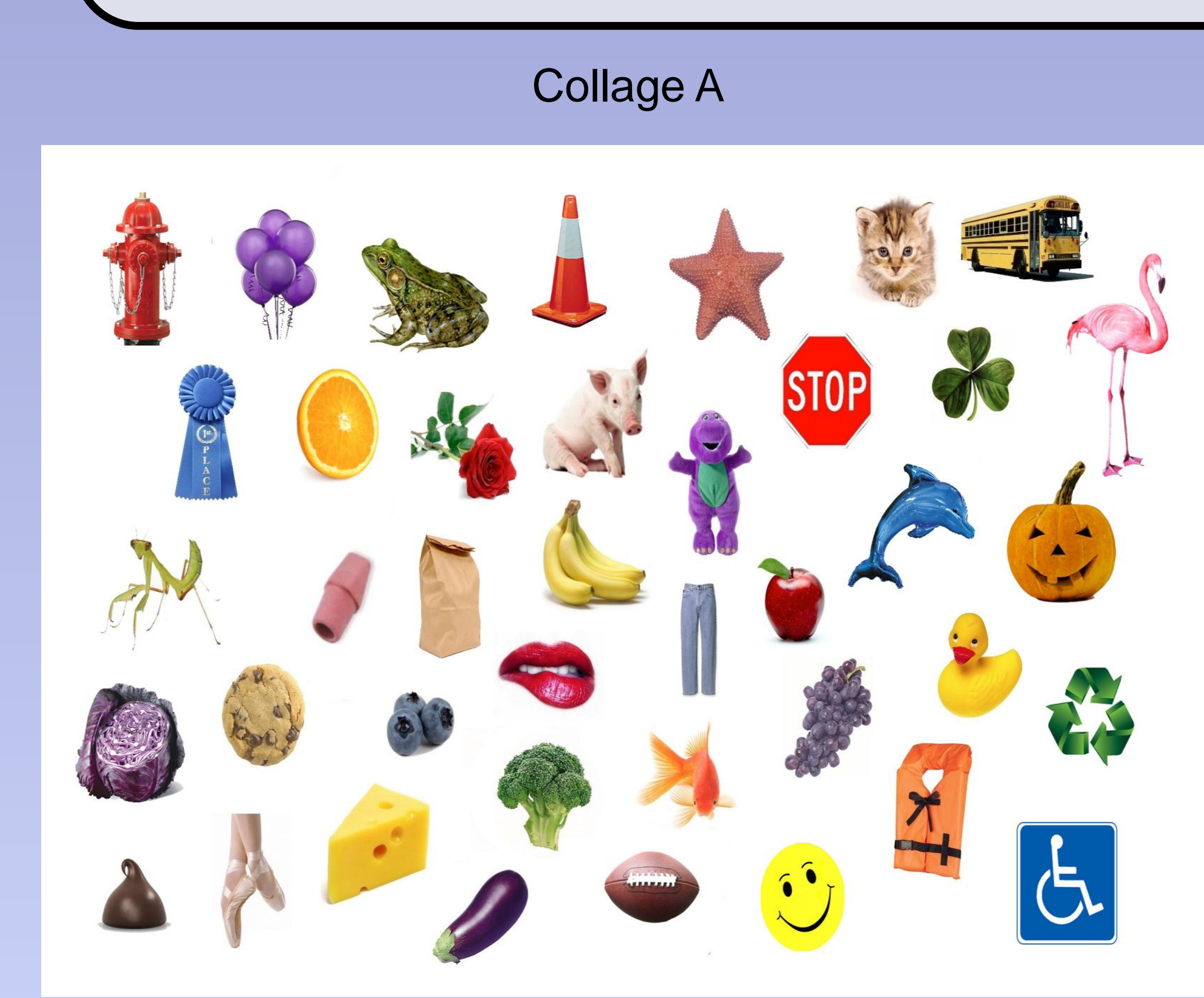

Collage B

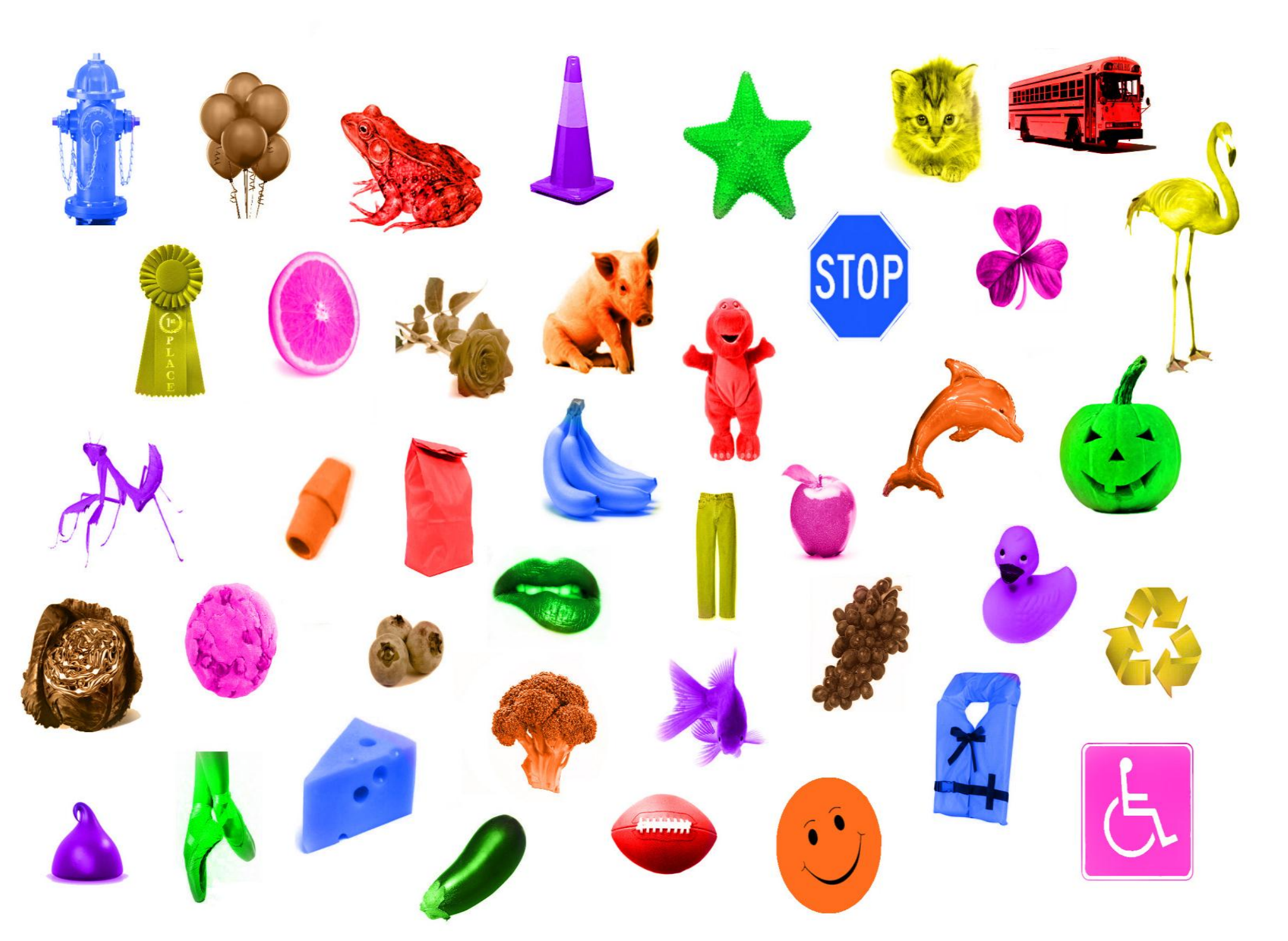

Table 1 - Tests of Between Subjects Effects Group \& Gender

Test of Between-Subjects Effects

\begin{tabular}{|c|c|c|c|c|c|}
\hline \multicolumn{6}{|c|}{ Test of Between-Subjects Effects } \\
\hline \multicolumn{6}{|c|}{ Dependent Variable: totalremembered } \\
\hline Source & $\begin{array}{c}\text { Type III Sum of } \\
\text { Squares }\end{array}$ & $\mathrm{Df}$ & Mean Square & $\mathrm{F}$ & Sig. \\
\hline Corrected Model & $135.443^{\mathrm{a}}$ & 3 & 45.148 & 4.656 & .004 \\
\hline Intercept & 7944.964 & 1 & 7944.964 & 819.300 & .000 \\
\hline Group & 115.841 & 1 & 115.841 & 11.946 & .001 \\
\hline Gender & 25.407 & 1 & 25.407 & 2.620 & 108 \\
\hline Group*gender & 10.449 & 1 & 10.449 & 1.077 & .301 \\
\hline Error & 1124.882 & 116 & 9.697 & & \\
\hline Total & 12493.000 & 120 & & & \\
\hline Corrected total & 1260.325 & 119 & & & \\
\hline
\end{tabular}

Figure 1 - Number of Images Remembered Between Groups

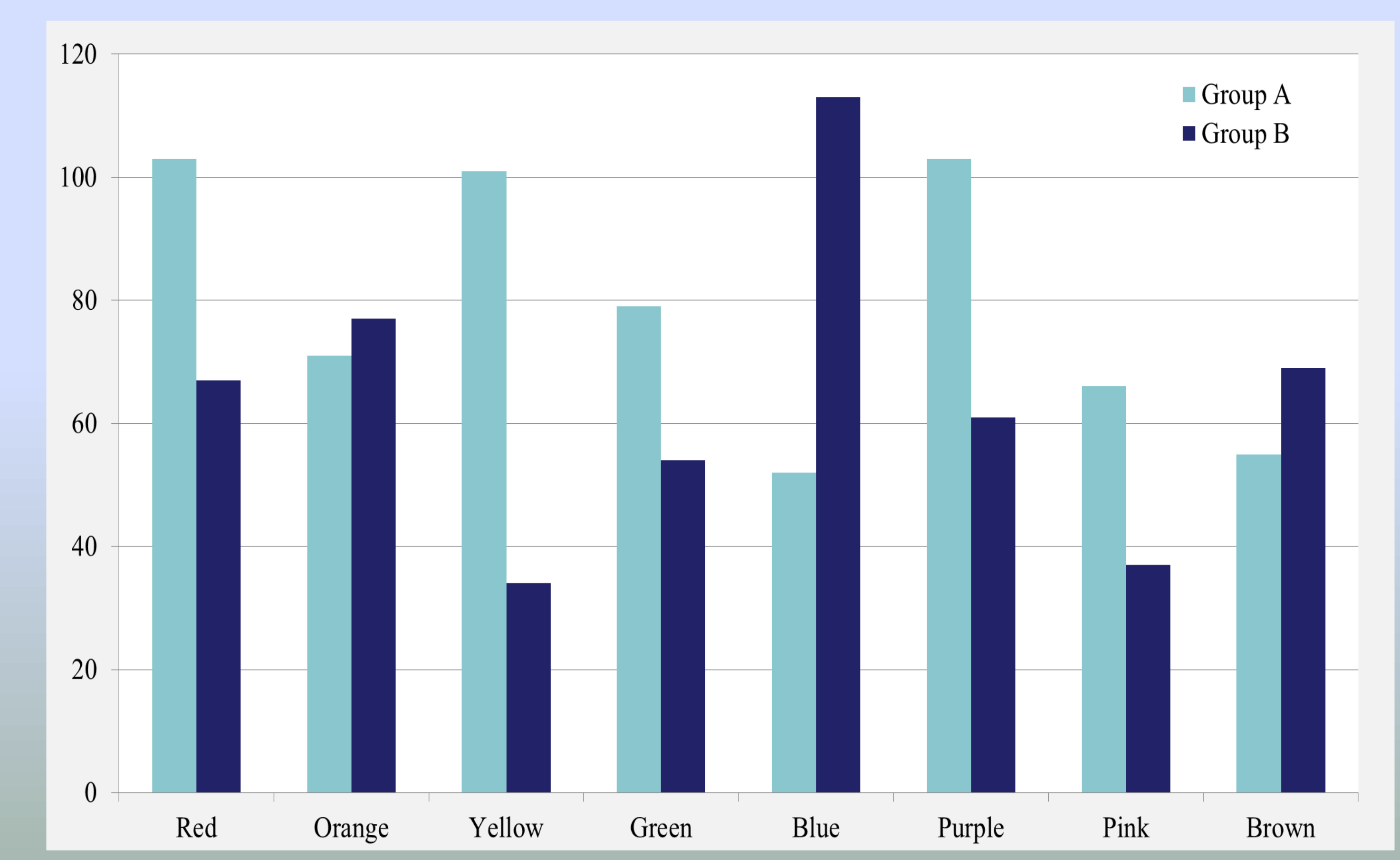

\section{RESULTS}

Overall Results

'We hypothesized that color would influence participants' ability to recall colored images. There was a significant difference in the number of items each team remembered.

Participants who viewed the commonly colored collage recalled a greater collage.

Analysis of Primary Hypothesis

- We hypothesized the control group (Group A) would be able to recall more images from memory than the experimental group (Group B). - ANOVA revealed a significant difference between groups, $F=11.946, p<$ .001. This indicated that Group $A$ was in fact able to recall more items than Group B, as we predicted.

Using this information we were able to reject the null hypothesis and infer that object color influenced participant memory.

Analysis of Secondary Hypotheses

- Gender was not an overall determinant in the number of items remembered, nor was it a determinant within groups as shown by effects within each group vielded 301. This effect was insignificant at the

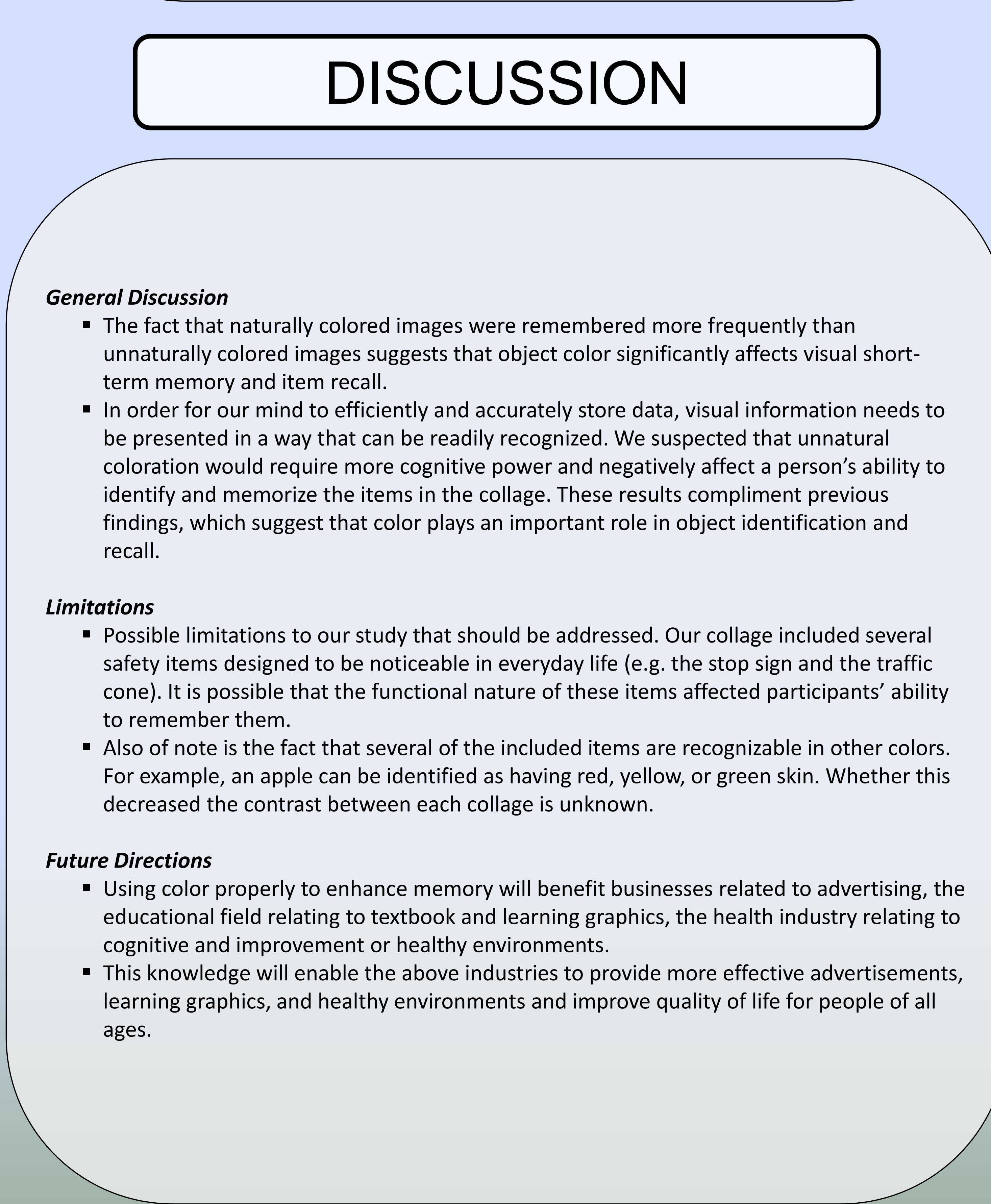

